\title{
Clinical, Radiographic and Magnetic Resonance Imaging Evaluation of Cervical Spine Trauma
}

ADITI HIMAUNSHU DONGRE, ATUL TUKARAM TAYADE, SUSHIL KUMAR KALE

\section{ABSTRACT}

Introduction: Cervical spine trauma occurs in 1.5 to $3 \%$ of patients with major trauma and in $10 \%$ of patients with major trauma and serious head injury. Imaging plays an important role in the diagnosis of spinal injuries. The various modalities used to evaluate cervical spine are plain radiography, computed tomography, CT myelography, intraoperative sonography and magnetic resonance imaging.

Aim: This study compares the usefulness of conventional radiography and MR imaging in the diagnosis of acute cervical spine trauma.

Materials and Methods: This prospective analytical study was carried out on 58 patients with history of cervical spine trauma. Evaluation was done on plain radiography and MR imaging. Findings were recorded on both the modalities and clinical correlation was done.

Results: In this study, $94.83 \%$ were males. Hyperflexion injuries were seen in $37.93 \%$ patients.C6 vertebral fracture was seen in $12 \%$ patients. Herniation of the disc was commonly seen at C4-5 and C5-6 disc level on MRI. 64 levels were found to be affected with simple cord edema.

Conclusion: MRI combined with plain radiographs provides an accurate and non invasive modality for evaluation of patients with cervical spine trauma.

\section{INTRODUCTION}

The cervical spine is injured in 3\% of major trauma patients [1]. Falls are the most important cause followed by motor vehicle accidents and violent acts [2]. Traumatic spine injury occurs at an annual rate of 20-40 persons per year, most are males in their teens or twenties. More than half of cord injuries occur in the cervical spine region, a third in the thoracic region and the remainder in the lumbo-sacral region. Quadriplegia is one of the most devastating consequences of cervical spine trauma. For those who survive, it is estimated that the cost of supportive care for life time of each quadriplegic patient will be from 1 to 5 million dollars [3].

Imaging plays an important role in the diagnosis of spinal injuries. Over the past two decades, there has been a renewed interest in diagnosis and treatment in patients of spine and spinal cord injuries. At present the various modalities used to evaluate the spine are plain radiography, computed tomography, CT myelography, intraoperative sonography and magnetic resonance imaging [4].

MR imaging, both low and high field strength is of increasing utility in evaluation of acute injuries to the cervical spine. In the past, MR imaging was being perceived as incompatible with the unpredictable clinical status and intensive monitoring requirements for the patients, which was difficult in the Magnet room. But today, MR imaging allows the spine to remain immobile until its stability is known and does not present the potential dangers of the radiographic flexion extension studies. The importance of Magnetic resonance imaging and different spinal cord signal changes seen on MRI have been shown to clinically correlate with the neurological symptoms [5]. MR is also essential for the imaging of patients with spinal cord injury without radiographical abnormality [6]. The rationale of this study was to determine the role of MRI in prospective evaluation of patients who presented with cervical spine trauma and to compare and correlate findings of MRI with those of conventional radiographic assessment along with clinical correlation.

\section{MATERIALS AND METHODS}

The present prospective analytical study was carried out in the Department of Radio diagnosis, Mahatma Gandhi Institute of Medical Sciences, Sewagram from July 2008 to July 2011 over a period of 3 years. Inclusion criterias were. patients with cervical spine trauma having stable vital parameters. Exclusion criteria includes unstable patients not fit for MR examination, history of cervical spine surgery and patients having cardiac pacemakers or angioplastic stents. Fifty eight patients of 
either sex, with history of cervical spine trauma were clinically evaluated and subjected to conventional radiography and Magnetic resonance imaging. The approval for the study was obtained from the institutional ethical committee. Explained written consent was obtained from all the patients.

Clinical examination, including the vital parameters and detailed neurological examination was done and ASIA impairment motor score [Table/Fig-1] was used as measurement tool [7]. Radiography was done using the three standard views; Antero-posterior, lateral and open mouth for C1-C2 vertebra. MRI was done on 0.2 Tesla SIEMENS concerto 2002 B Magnetom MRI machine. The cervical spine was assessed on radiography and $\mathrm{MRI}$ for curvature, alignment, fractures, locked facets and prevertebral soft tissue. In addition to this ligament injury, traumatic disc herniation, pre and paravertebral hemorrhage, spinal cord injury, and epidural hemorrhage were noted on MRI. All findings were correlated. Data obtained was evaluated by Kappa test and Chi-square test.

\section{RESULTS}

In this study, $51 \%$ of cases fell in the age group of $21-40$ years and $94.83 \%$ were males. Fall was seen in $37.93 \%$ patients followed by motor vehicle accidents seen in $36.21 \%$ patients. Maximum number of patients presented with neck pain (79.31\%) followed by limb weakness (77.59\%). Hyperflexion injuries were seen in $37.93 \%$ patients followed by hyperextension in $20.69 \%$ patients. There were 34 (58.62\%) patients in the group who had Grade A injury, 5 patients (8.62\%) in Grade B, 6 patients (10.34\%) in Grade C, 5 patients (8.62\%) in Grade D and 8 (13.79\%) patients in Grade E according to ASIA. C6 vertebral fracture was seen in 12\% patients [Table/ Fig-2,3]. Increased prevertebral soft tissue edema was seen in 29.31\% patients and locked facets were mainly seen at C5-6, C6-7 levels (13.8\%). Out of the 58 patients the interspinous ligament was injured in $24.14 \%$ patients. Herniation of the

\begin{tabular}{|l|l|l|}
\hline Grade & Extension & Neurologic Evaluation \\
\hline A & Complete & $\begin{array}{l}\text { No motor or sensory function preserved in sacral } \\
\text { segments S4-S5 }\end{array}$ \\
\hline B & Incomplete & $\begin{array}{l}\text { Sensory but not motor function is preserved } \\
\text { below the neurological level and includes sacral } \\
\text { segments S4-S5 }\end{array}$ \\
\hline C & Incomplete & $\begin{array}{l}\text { Motor function is preserved below the neurologic } \\
\text { level, and more than half of key muscles below the } \\
\text { neurologic level have a muscle grade of less than 3. }\end{array}$ \\
\hline D & Incomplete & $\begin{array}{l}\text { Motor function is preserved below the } \\
\text { neurologic level, and at least half of key } \\
\text { muscles below the neurologic level have a } \\
\text { muscle grade of 3 or more. }\end{array}$ \\
\hline E & Normal & Motor and sensory functions are normal. \\
\hline
\end{tabular}

[Table/Fig-1]: American Spinal Injury Association impairment scale for neurologic and functional classification of spinal cord injury [7]. disc was commonly seen at C4-5 and C5-6 disc level on MRI. $6.9 \%$ patients had epidural hemorrhage at 5 levels on MRI. 64 levels were found to be affected with simple cord edema [Table/Fig-4]. The next common injury was cord compression with edema which was seen at 62 levels.
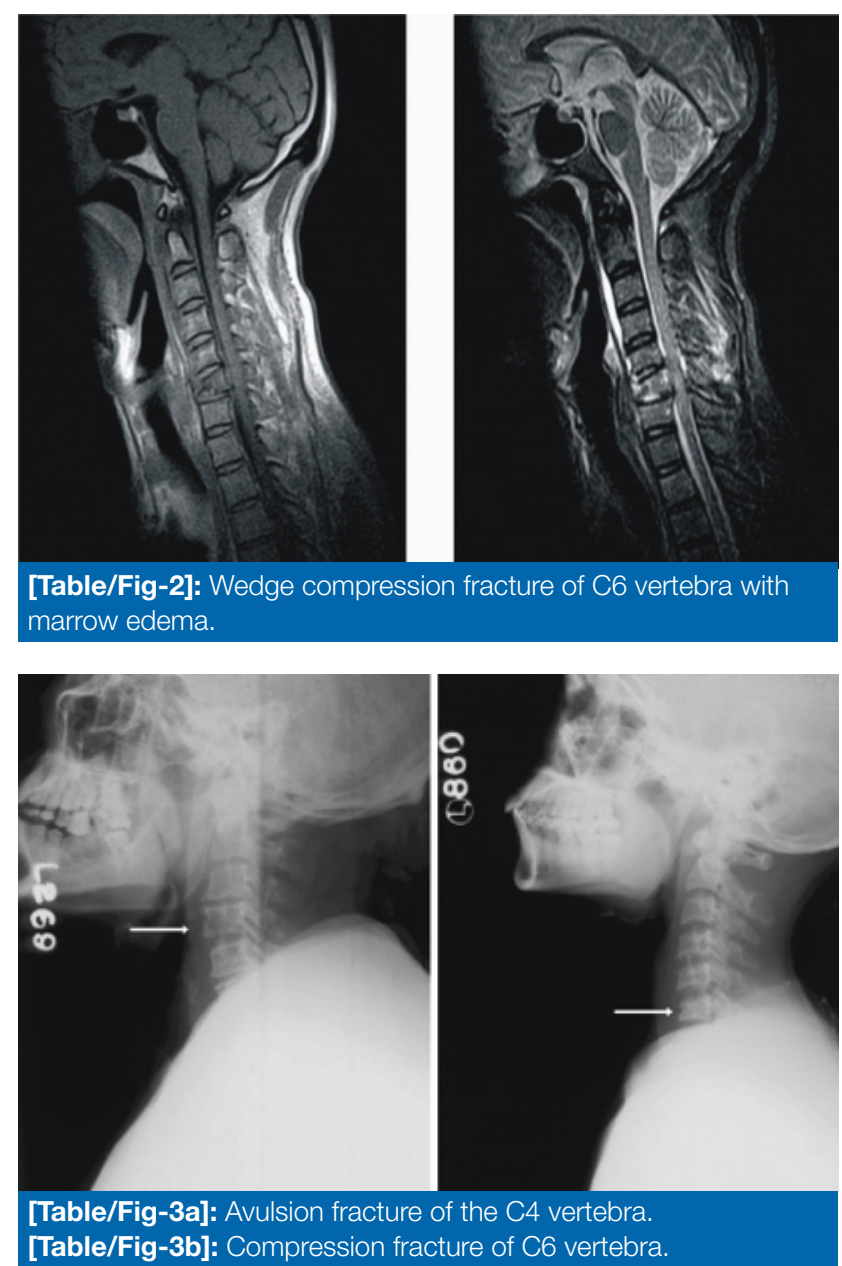

\section{DISCUSSION}

The mean age of the study population was 42.51 years. The maximum number of cases fell in the age group of 2140 years. There was a male sex predilection owing to their increased outdoor activities.

This was also noted in studies by Flanders et al., [8] and Kulkarni et al., [9]. The most common mode of injury was fall from height causing hyper flexion injury. This observation was similar to studies done by Yasuyuki Yamashita et al., [10] and Shrestha et al., [11].

The patients presented predominantly with neck pain and quadriplegia and maximum number of patients belonged to ASIA Grade A, Complete injury. A study by Firoz Miyanji et al., [12] showed, that maximum percentages of patients were found in category B, C, D of ASIA Motor score. This 

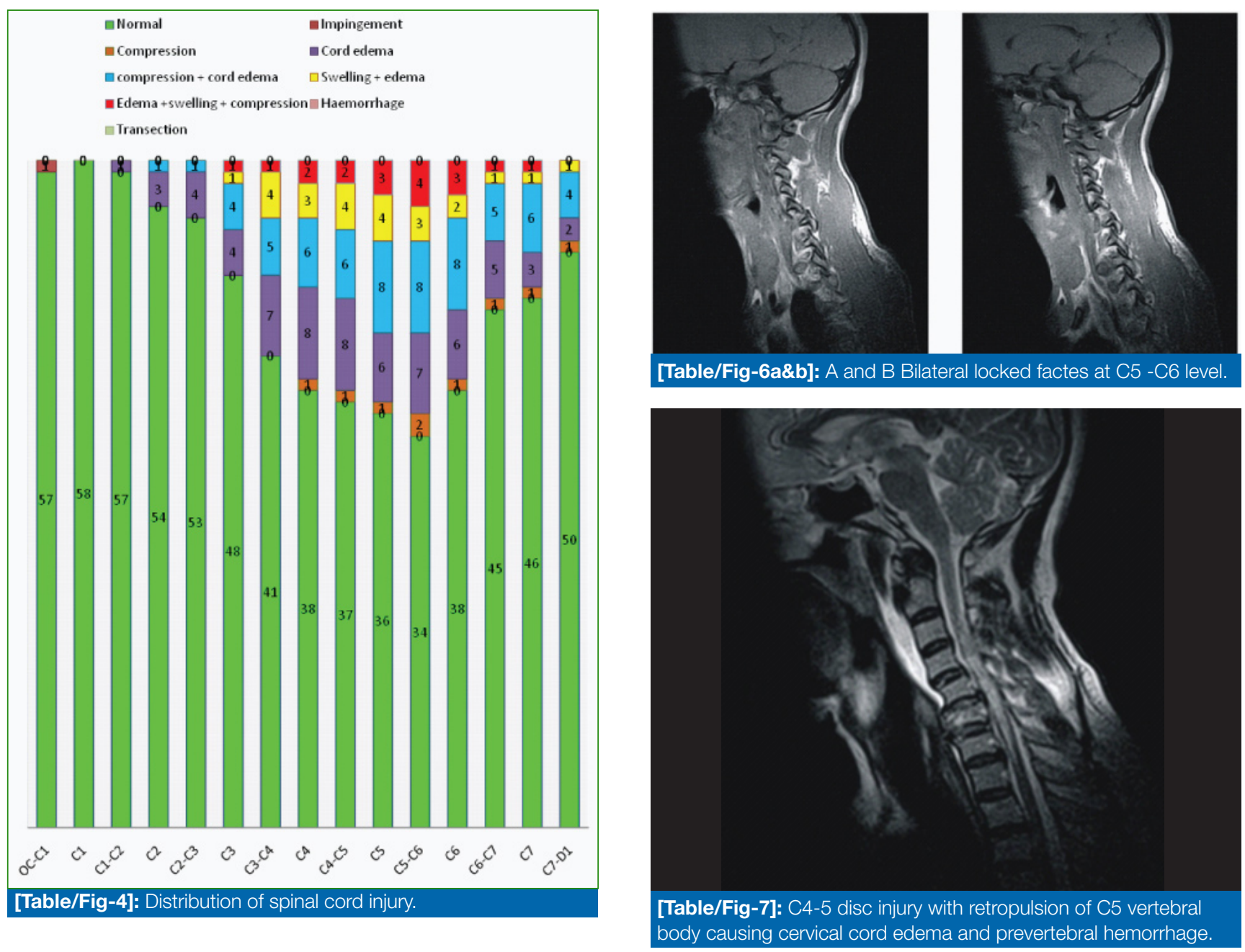

\begin{tabular}{|c|c|c|c|}
\hline \multicolumn{4}{|c|}{ 1. Curvature on MRI } \\
\hline 1. Curvature on radiography & Normal- 36 & Loss of lordotic curvature -8 & Straightening-14 \\
\hline \multicolumn{4}{|c|}{ 2. Vertebral fracture on MRI } \\
\hline 2. Vertebral fracture on Radiography & Absent & Present & Total \\
\hline Absent & 40 & 0 & 40 \\
\hline Present & 3 & 15 & 18 \\
\hline Total & 43 & 15 & 58 \\
\hline \multicolumn{4}{|c|}{ 3. Locked facets on MRI } \\
\hline 3. Locked facets on radiography & Absent & Present & Total \\
\hline Absent & 51 & 0 & 51 \\
\hline Present & 4 & 3 & 7 \\
\hline Total & 55 & 3 & 58 \\
\hline \multicolumn{4}{|c|}{ 4. Prevertebral soft tissue edema on MRI } \\
\hline 4. Prevertebral Thickness on radiography & Absent & Present & Total \\
\hline Absent & 31 & 9 & 40 \\
\hline Present & 1 & 17 & 18 \\
\hline Total & 32 & 26 & 58 \\
\hline
\end{tabular}




\begin{tabular}{|c|c|c|c|c|c|c|c|c|c|c|c|c|c|c|c|}
\hline Spinal cord lesion & $\mathrm{OC}_{\mathrm{C} 1}^{-}$ & C1 & $\begin{array}{c}\text { C1 } \\
2\end{array}$ & $\mathrm{C} 2$ & $\mathrm{C} 2-3$ & C3 & C3 - 4 & $\mathrm{C} 4$ & $\begin{array}{c}\mathrm{C} 4- \\
5\end{array}$ & C5 & $\begin{array}{l}\text { C } 5 \\
-6\end{array}$ & C6 & $\begin{array}{c}\text { C6 } \\
7\end{array}$ & $\mathrm{C7}$ & ${ }^{C 7}$ \\
\hline Normal & 57 & 58 & 57 & 54 & 53 & 48 & 41 & 38 & 37 & 36 & 34 & 38 & 45 & 46 & 50 \\
\hline Impingement & 1 & 0 & 0 & 0 & 0 & 0 & 0 & 0 & 0 & 0 & 0 & 0 & 0 & 0 & 0 \\
\hline Compression & 0 & 0 & 0 & 0 & 0 & 0 & 0 & 1 & 1 & 1 & 2 & 1 & 1 & 1 & 1 \\
\hline Edema & 0 & 0 & 1 & 3 & 4 & 4 & 7 & 8 & 8 & 6 & 7 & 6 & 5 & 3 & 2 \\
\hline Compression + edema & 0 & 0 & 0 & 1 & 1 & 4 & 5 & 6 & 6 & 8 & 8 & 8 & 5 & 6 & 4 \\
\hline Swelling+ edema & 0 & 0 & 0 & 0 & 0 & 1 & 4 & 3 & 4 & 4 & 3 & 2 & 1 & 1 & 1 \\
\hline Edema+ swelling+ compression & 0 & 0 & 0 & 0 & 0 & 1 & 1 & 2 & 2 & 3 & 4 & 3 & 1 & 1 & 0 \\
\hline Hemorrhage & 0 & 0 & 0 & 0 & 0 & 0 & 0 & 0 & 0 & 0 & 0 & 0 & 0 & 0 & 0 \\
\hline Transection & 0 & 0 & 0 & 0 & 0 & 0 & 0 & 0 & 0 & 0 & 0 & 0 & 0 & 0 & 0 \\
\hline
\end{tabular}

[Table/Fig-8]: Distribution of patients according to spinal cord injury on MRI

deferred from our study which could be attributed to the early and prompt reporting of patients in Western countries as opposed to delay in reporting to the medical facility and medical unawareness in India. Thus only severe injuries are reported in hospitals.

The commonest fractured vertebra was C6 vertebra. Plain radiography was superior in detecting fractures as compared to MRI. Therefore, we recommend plain radiography should be done in all cervical trauma patients in order to detect fractures.

However, it over estimated the locked facets [Table/Fig-5]. $\mathrm{MRI}$ was more accurate in depicting the locked facets due to sequential saggital imaging [Table/Fig-5,6a\&b] MRI was also superior in detecting the prevertebral soft tissue edema owing

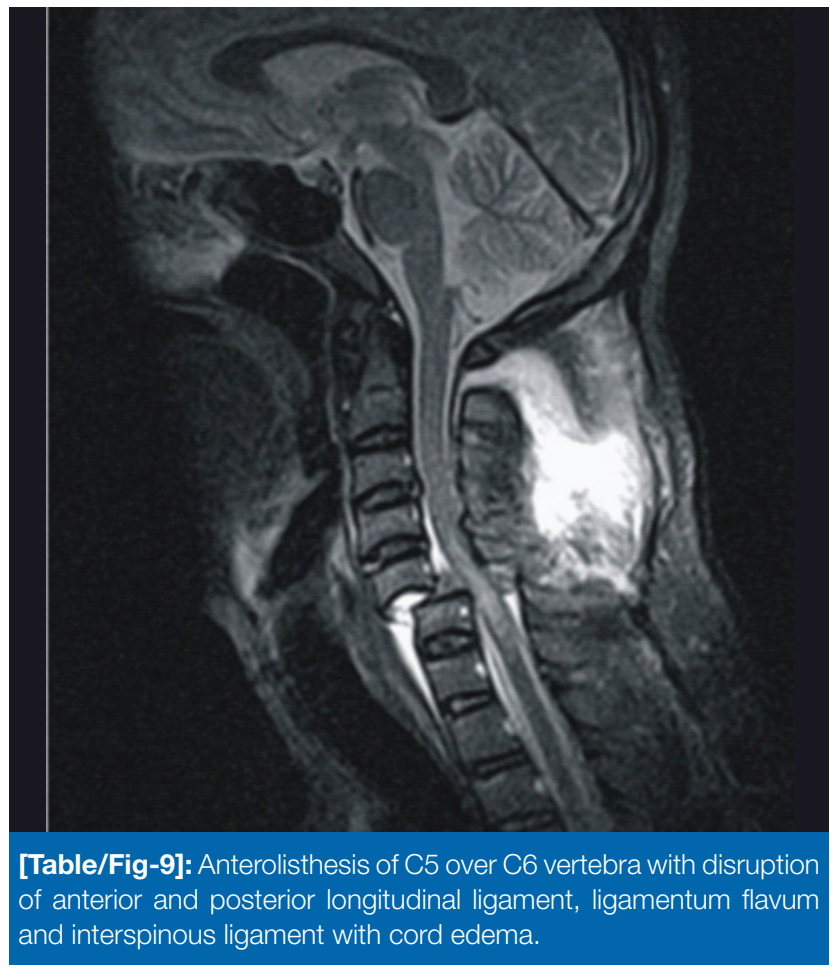

to its higher soft tissue contrast [Table/Fig-5,7]. Simple cord edema was the most common cord injury which could have been attributed to less severe form of injury and favorable prognosis [Table/Fig-8]. The next common injury was cord compression with edema [Table/Fig-7]. None of the patients had cord hemorrhage or cord transection. Canal stenosis was diagnosed equally on both radiography and MRI.

The interspinous ligament was the commonest ligament to be injured followed by anterior longitudinal ligament [Table/Fig-9]. The weakness in all the limbs clinically correlated well with spinal cord edema on MRI. A statistical significant correlation ( $p$-value $\leq 0.015$ ) was found between weakness in limbs and $\mathrm{MRI}$ evidence of spinal cord edema. Out of 34 patients having complete spinal cord injury, 33 patients had cord edema which was highly statistically significant ( $p$-value $\leq 0.00001$ ).

Our study revealed that in those patients who had weakness in all limbs, had cord edema on MRI $(p=0.015)$. Neck pain was associated with disc herniation $(p=0.013)$ and spinal cord edema ( $p$-value $\leq 0.034$ ). The bony spinal canal compromise $(p$-value $\leq 0.03)$ and spinal cord edema ( $p$-value $\leq 0.00001)$ also clinically correlated with ASIA grade. Statistically significant correlation ( $p$-value $\leq 0.02$ ) was found between pre vertebral soft tissue injury and ASIA Grade. Our study confirms the clinical feasibility and utility of low strength MR imaging as available option in rural area in the initial assessment of cervical spine trauma but seeks to emphasize the continued importance of conventional radiography in detecting vertebral fractures.

\section{CONCLUSION}

$\mathrm{MRI}$ combined with plain films provides an accurate and non invasive modality for evaluation of patients with cervical spine trauma and can be used as a primary modality of choice.

\section{ACKNOWLEDGMENTS}

I am grateful to the patients who allowed me to undergo the radiographs and MRls inspite of their pain and suffering. I am 
also thankful to the technicians who helped me to carry out the studies and last but not the least my husband who helped me to concisely write the thesis.

\section{REFERENCES}

[1] Crim JR, Moore K, Brodke D. Clearance of the cervical spine in multitrauma patients: the role of advanced imaging. Semin Ultrasound CT MR. 2001; 22(4):283-305.

[2] Fredø HL, Rizvi SA et al. The epidemiology of traumatic cervical spine fractures: a prospective population study from Norway. Scand J Trauma Resusc Emerg Med. 2012; 20-85.

[3] Bachulis BL, Long WB, Hynes GD, Johnson MC. Clinical indications for cervical spine radiographs in the traumatized patient. Am J Surg. 1987;153:473-78.

[4] Mirvis SE, Shanmuganathan K. Trauma radiology: Part V. Imaging of acute cervical spine trauma. J Intensive Care Med. 1995; 10(1):15-33.

[5] Kim KS, Lee JH, Kim WJ et al. The role of MRI in spinal cord injury without radiographic abnormality. J Korean Soc Emerg Med. $2004 ;$ 15(5):311-16.

[6] Mahmood N S, Rajagopal K, Ramesh AK. Cervical spinal cord injury with and without the radiographical evidence of trauma -a retrospective comparative study in adults. Journal of Clinical and Diagnostic Research. 2010;(4): 2183-89.
[7] American Spinal Injury Association, International Medical Society of Paraplegia (ASIA / IMSOP). International standards for neurological and Functional classification of spinal cord injury. Revised 1992. American Spinal Injury Association. Chicago III.

[8] Flanders AE, Schaefer DM, Doan HT, Mishkin MM, Gonzalez CF, Northrup BE. Acute cervical spine trauma: Correlation of MR imaging findings with degree of neurologic deficit. Radiology. 1990;177:25-33.

[9] Kulkarni MV, Bondurant FJ, Rose SL, Narayana PA. 1.5 tesla magnetic resonance imaging of acute spinal trauma. Radiographics.1988;8:1059-82.

[10] Yamashita Y, Takahashi M, Matsuno Y, Sakamoto Y, Oguni T, Sakae T, Yoshizumi K, Kim EE. Chronic injuries of the spinal cord: assessment with MR imaging. Radiology.1990;175:849-54.

[11] Shreshtha D, Garg M, Singh G. K., Singh M. P., U.K. S. Cervical spine injuries in ateaching hospital of Eastern region of Nepal : A Clinico-Epidemiological study. Journal of Nepal Medical Association. 2007;46:107-11.

[12] Miyanji F, Furlan JC, Aarabi B, Arnold PM, Fehlings MG. Acute cervical traumatic spinal cord injury: MR imaging findings correlated with neurologic outcome--prospective study with 100 consecutive patients. Radiology. 2007;243:820-27.

\section{AUTHOR(S):}

1. Dr. Aditi Himaunshu Dongre

2. Dr. Atul Tukaram Tayade

3. Dr. Sushil Kumar Kale

\section{PARTICULARS OF CONTRIBUTORS:}

1. Assistant Professor, Department of Radiology, SKNMC, Narhe, Pune, India.

2. Professor and Head, Department of Radiology, Mahatma Gandhi Institute of Medical Sciences, Sewagram, Wardha, India.

3. Professor, Department of Radiology, Mahatma Gandhi Institute of Medical Sciences, Sewagram, Wardha, India.

\section{NAME, ADDRESS, E-MAIL ID OF THE CORRESPONDING AUTHOR:}

Dr. Aditi Himaunshu Dongre, Assistant Professor, Department of Radiology, SKNMC, Narhe, Pune-411041, India.

E-mail: aditi.dongre@gmail.com

FINANCIAL OR OTHER COMPETING INTERESTS: None. 